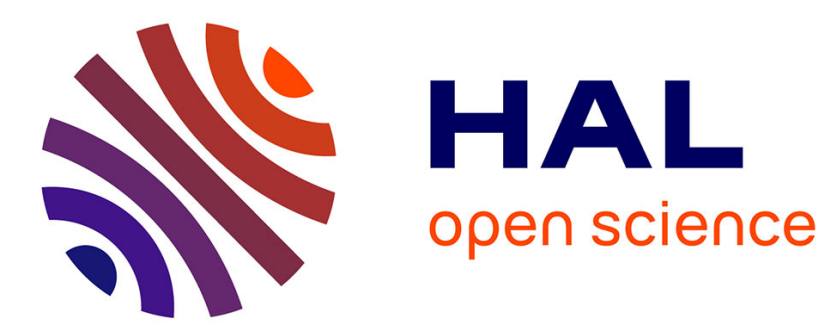

\title{
Organogel formation rationalized by Hansen solubility parameters: dos and don'ts
}

Julien Bonnet, Gad Suissa, Matthieu Raynal, Laurent Bouteiller

\section{To cite this version:}

Julien Bonnet, Gad Suissa, Matthieu Raynal, Laurent Bouteiller. Organogel formation rationalized by Hansen solubility parameters: dos and don'ts. Soft Matter, 2014, 10, pp.3154-3160. $10.1039 / \mathrm{c} 4 \mathrm{sm} 00244 \mathrm{j}$. hal-01122532

\section{HAL Id: hal-01122532 https://hal.sorbonne-universite.fr/hal-01122532}

Submitted on 4 Mar 2015

HAL is a multi-disciplinary open access archive for the deposit and dissemination of scientific research documents, whether they are published or not. The documents may come from teaching and research institutions in France or abroad, or from public or private research centers.
L'archive ouverte pluridisciplinaire HAL, est destinée au dépôt et à la diffusion de documents scientifiques de niveau recherche, publiés ou non, émanant des établissements d'enseignement et de recherche français ou étrangers, des laboratoires publics ou privés. 


\title{
Organogel formation rationalized by Hansen solubility parameters: dos and don'ts
}

\author{
Julien Bonnet, ${ }^{\mathrm{a}, \mathrm{b}}$ Gad Suissa, ${ }^{\mathrm{a}, \mathrm{b}}$ Matthieu Raynal ${ }^{\mathrm{a}, \mathrm{b}}$ and Laurent Bouteiller ${ }^{\mathrm{a}, \mathrm{b}}$ *
}

Some organic compounds gelate liquids by forming a network of anisotropic fibres. Hansen solubility parameters can be used to predict the range of liquids that are likely to be gelled by any given gelator. We critically review the various approaches recently proposed in the literature. In particular, we discuss the shape of the gelation domain, the relevance of the Teas plot representation and use of group contribution 10 calculations. We also propose an improved scheme for the solubility tests, and a detailed procedure for the determination of the gelation domain.

\section{Introduction}

Organogels are obtained when a limited amount of a low molecular weight gelator (LMWG) is dispersed in a liquid where it self-assembles into elongated fibrillar structures, that form an entangled network. ${ }^{1,2}$ These gels are often thermally reversible and show a rich variety of rheological properties going from a purely elastic to a thixotropic or viscoelastic behaviour. ${ }^{3-7}$ Such fibrillar structures are highly promising candidates for a wide range of applications ${ }^{8,9}$ such as drag reducing agents, ${ }^{10}$ biomaterials, ${ }^{11,12}$ stimuli-responsive materials, ${ }^{11,13-19}$ sensors, ${ }^{14,16-}$ $18,20,21$ templating components for organic or inorganic nanostructures, ${ }^{22,23}$ liquid crystalline materials, ${ }^{24,25}$ optoelectronic materials, ${ }^{26-29}$ host-guest systems, ${ }^{30}$ and in the field of catalysis. $^{31,32}$ They can even be used to improve the mechanical properties of soft solids. ${ }^{33}$

To date, a wide range of LMWGs are known, but most of them have been discovered by serendipity. As a matter of fact, it is still difficult to design a gelator de novo to yield a gel in a specific liquid. In contrast, we now have guiding principles to predict if a previously described LMWG will gelate an untested liquid, based on the known ability of the LMWG to gelate a range of more or less similar liquids. Early attempts to rationalize the gelling power of a LMWG were proposed based on various solubility indicators: dielectric constant, ${ }^{34-36}$ Reichardt's polarity scale $\left(E_{\mathrm{T}}\right){ }^{36}$ Hildebrand solubility parameter, ${ }^{36,37}$ Kamlet-Taft parameters, ${ }^{36,38-39}$ Hansen solubility parameters (HSPs), ${ }^{36,40}$ dissolution enthalpy and entropy. ${ }^{41}$ Each of these attempts was focused on a particular LMWG family, and while the conclusions are of interest, they cannot easily be applied to other LMWGs. In contrast, we recently extended the HSP approach and showed that it is possible to predict the gelling ability of any LMWG based on its behaviour in a limited set of solvents. ${ }^{42}$ Since then, several groups have tested our approach with new LMWGs and have confirmed the validity of the concept. ${ }^{43-46}$ However, some concerns have been expressed about the mathematical difficulties involved in the method, ${ }^{47,48}$ while several studies have proposed related approaches. ${ }^{47-56}$ Therefore, the objective of the present report is both to better explain our approach to make it more accessible and to critically discuss the recent developments in the field.

\section{General comments on the method}

The basic principle

For several decades, HSPs have been successfully used in the field of polymer science to select solvents for various applications. ${ }^{57,58}$ In this approach, molecular interactions are categorized into three groups: dispersive interactions $\left(\delta_{d}\right)$, polar interactions $\left(\delta_{p}\right)$ and hydrogen bonds $\left(\delta_{h}\right)$. In practice, the procedure consists in comparing the HSPs for the solvent $\left(\delta_{d}^{s}, \delta_{p}^{s}\right.$, $\left.\delta_{h}^{S}\right)$ to the HSPs for the polymer $\left(\delta_{d}, \delta_{p}, \delta_{h}\right)$. If the distance between the two points in Hansen space (defined as $R=$ $\left.\sqrt{4\left(\delta_{d}-\delta_{d}^{S}\right)^{2}+\left(\delta_{p}-\delta_{p}^{s}\right)^{2}+\left(\delta_{h}-\delta_{h}^{S}\right)^{2}}\right)$ is smaller than an empirical and case specific value $R_{\text {Sol }}$, then the polymer and the solvent have a high probability of being miscible. The values for the HSPs of liquids can be found in the literature, ${ }^{57,59}$ and the values for the polymer are determined by testing the solubility of the polymer in a range of liquids and plotting the results in a $3 \mathrm{D}$ representation, with $\delta_{d}^{s}, \delta_{p}^{s}$ and $\delta_{h}^{s}$ as axes (the Hansen space). The points for the good solvents tend to cluster in a particular region in space, thus defining a solubility sphere for the polymer, with $\left(\delta_{d}, \delta_{p}, \delta_{h}\right)$ as its centre and $R_{\mathrm{Sol}}$ as its radius. ${ }^{57-59}$

After dissolution of a LMWG in a liquid at an elevated temperature and subsequent cooling, a gel may form rather than a solution or a precipitate, if solute-solvent and solute-solute interactions are suitably balanced. ${ }^{60-63} \mathrm{We}$ can therefore guess that in a favourable domain in Hansen space, the liquids are gelated because they do not compete too much with inter-gelator interactions, but still allow dissolution at high temperature. We have actually proved through extensive literature data analysis that there is a strong correlation between HSPs and gel formation. ${ }^{42}$ The method consists in plotting the solubility data in Hansen space, where each liquid is represented by a point of coordinates $\left(\delta_{d}^{S}, \delta_{p}^{s}, \delta_{h}^{S}\right)$ and labelled according to the group it belongs to: $\mathrm{S}$ (solution forming), I (either insoluble or formation of a precipitate after cooling) and $\mathrm{G}$ (gel forming). The good solvents (S) tend to cluster in a particular region of space, whereas the gelating liquids $(\mathrm{G})$ tend to cluster in a distinct 
region of space (or sometimes two regions).

H

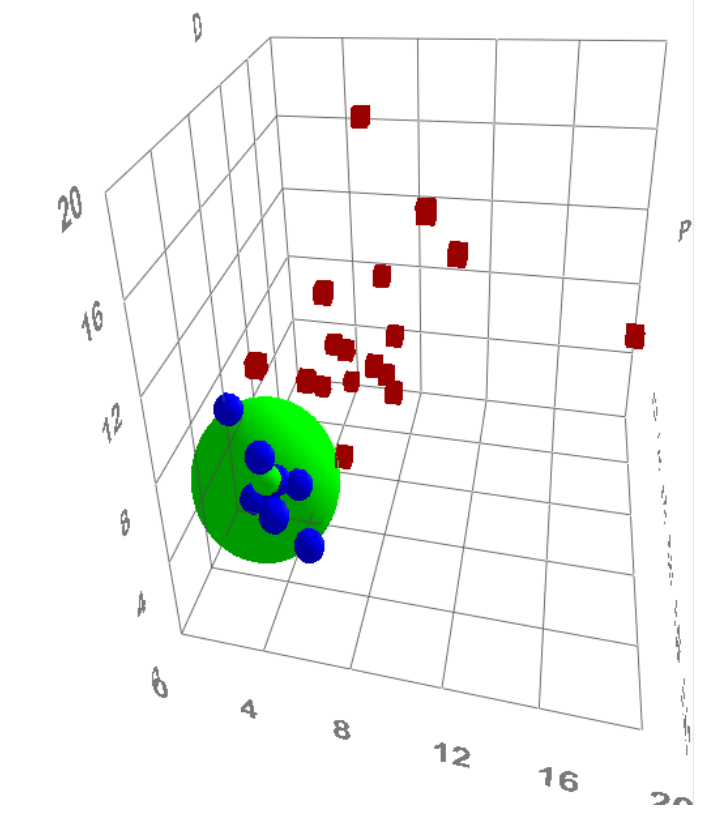

20

D

4

16

12

8

4

10
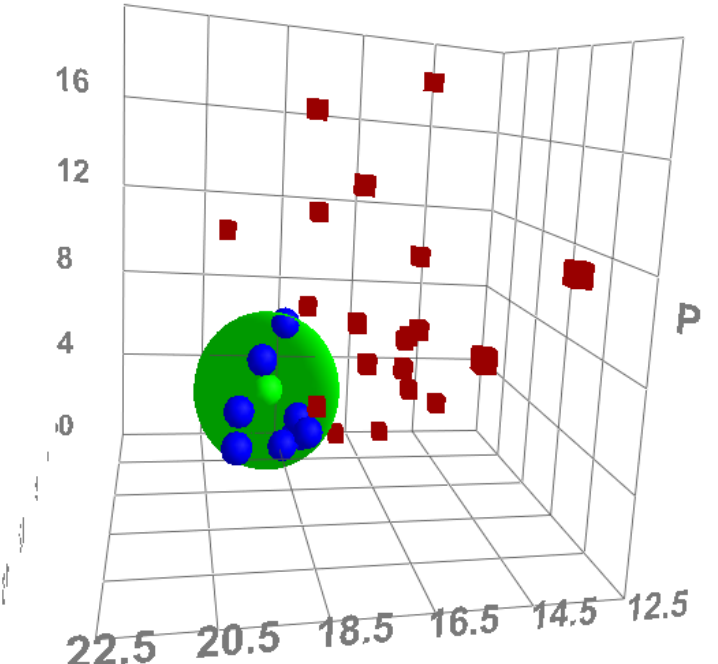

22.5

\begin{abstract}
Fig. 1 Solubility data from Jamart-Grégoire et al..$^{50}$ for amino acid based LMWG $1 \mathrm{a}(5 \mathrm{~g} / \mathrm{L})$, represented in Hansen space. The gelated liquids $(\mathrm{G})$ are represented by blue points; both good solvents $(\mathrm{S})$ and non-solvents (I) are represented by red points. The gelation sphere is green and its centre is light green. The plot is generated with the HSPiP software. ${ }^{59}$
\end{abstract}

In order to turn this plot into a predictive tool, a model is needed. By analogy with the polymer solubility sphere, the centre and the radius of a gelation sphere can be determined so that as many $\mathrm{G}$ liquids as possible lie inside the sphere, but as many I and $\mathrm{S}$ liquids as possible lie outside (see below for the practical determination of the sphere). Fig. 1 shows the result of this approach applied to the data from an amino acid based LMWG recently reported by Jamart-Grégoire et $a .^{50}$ When the experimental data is comprehensive, as in this example, the gelation sphere is unambiguously defined and it can then be used to predict if an untested liquid (or liquid mixture ${ }^{46}$ ) will be gelated by this particular LMWG, according to whether its HSP coordinates fall inside or outside the gelation sphere. This straightforward approach considerably reduces the number of trials usually involved during the identification of a suitable gelator for a particular application, i.e. in a particular formulation. Moreover, it allows using the extensive solubility data available in the literature to predict if liquids of industrial interest can be gelled by a particular LMWG that was only tested in usual organic solvents.

Of course, as explained in our initial publication, ${ }^{42}$ it is also possible to determine a solubility sphere from the same data, but we will not focus on this feature here, as the main purpose of using LMWGs is to obtain gels.

\section{The shape of the gelation domain}

It is not clear to us whether the gelation domain should theoretically be a sphere or not. However, most experimental data available show compact and globular gelation domains, ${ }^{42-56}$ and the sphere is the mathematically most simple object that can be used to describe these domains. In a few cases however, a very elongated or even two discontinuous gelation domains have been identified. ${ }^{42,44}$ From a theoretical perspective, this is in fact not surprizing because a given gelator may not necessarily form fibres with the same crystalline structure in every tested liquid. ${ }^{51,64,65}$ Therefore, the functional groups of the gelator that are exposed at the fibre surface can actually depend on the gelated liquid, ${ }^{66}$ which obviously affects the interfacial energy. In such cases, several gelation domains can be expected: one gelation domain for each polymorphic form displayed by the fibres (for an example, see Fig. S1). From a practical standpoint, in these special situations, one can advantageously try to describe the gelation domain with an ellipsoid shape or with a pair of spheres.

\section{The importance of using all three HSPs}

Several authors have analysed their gel data in the light of HSPs but have unfortunately considered each parameter $\left(\delta_{d}^{s}, \delta_{p}^{s}, \delta_{h}^{s}\right.$ or $\left.\delta^{S}=\sqrt{\left(\delta_{d}^{S}\right)^{2}+\left(\delta_{p}^{S}\right)^{2}+\left(\delta_{h}^{S}\right)^{2}} \quad\right) \quad$ independently of the others. $^{36,40,50,51,55}$ Even if some correlation with a particular parameter exists, it is obvious that an improved description of the data is possible if all three parameters are used.

For example, Jamart-Grégoire et al. noticed a better correlation of the gelation behaviour of an amino acid based LMWG with $\delta_{h}^{s}$ than with any other parameter: with only a few exceptions, ${ }^{67}$ the liquids are gelled by LMWG 1a if and only if they are situated in the range $0.4<\delta_{h}^{S}<2.9 \mathrm{MPa}^{1 / 2}{ }^{50}$ While this is correct, Fig. 1 shows that the correlation is even better in a three dimensional plot: without a single exception, the liquids are gelled if and only if they are situated in the sphere of centre $\left(\delta_{d}=18.8, \delta_{p}=2.8\right.$, $\delta_{h}=2.1 \mathrm{MPa}^{1 / 2}$ ) and radius $R=3.8 \mathrm{MPa}^{1 / 2}$. Fig. S2 shows that the other gelator in this study is also perfectly described by a gelation sphere. Interestingly, the slight variation in gelator structure is translated into a slight shift of the gelation sphere, whereas the one-dimensional analysis based on $\delta_{h}^{S}$ does not capture this subtle effect.

While the use of a single HSP may be sufficient to describe a particular system, it is obvious it cannot be universal. For example, the hydrogen bond forming gelator of Jamart-Grégoire 
et al. was ruled (in a first approximation) by the hydrogen bonding parameter $\delta_{h}$ (see above), whereas the behaviour of polar oxadiazole gelators reported by Li et al. was reported to be better correlated to a combination of the hydrogen bond and polar parameters $\delta_{a}=\sqrt{\left(\delta_{p}\right)^{2}+\left(\delta_{h}\right)^{2}} \cdot{ }^{51}$ Unsurprisingly, both systems can be advantageously rationalized if all three HSPs are used (Figs. 1 and S3).

Even more eloquently, Fan et al. reported the absence of correlation between the gelation ability of a two-component LMWG in water/solvent mixtures and any HSP taken individually. ${ }^{48,52}$ While this is apparently correct, Fig. 2 shows that in a three dimensional plot all the gelled liquids are clustered in a region of high $\delta_{p}^{S}$ and intermediate $\delta_{h}^{S}$. In this particular example, the determination of a reliable gelation sphere is not feasible because of a lack of data; however, the correlation between gelation and position in Hansen space is obvious.

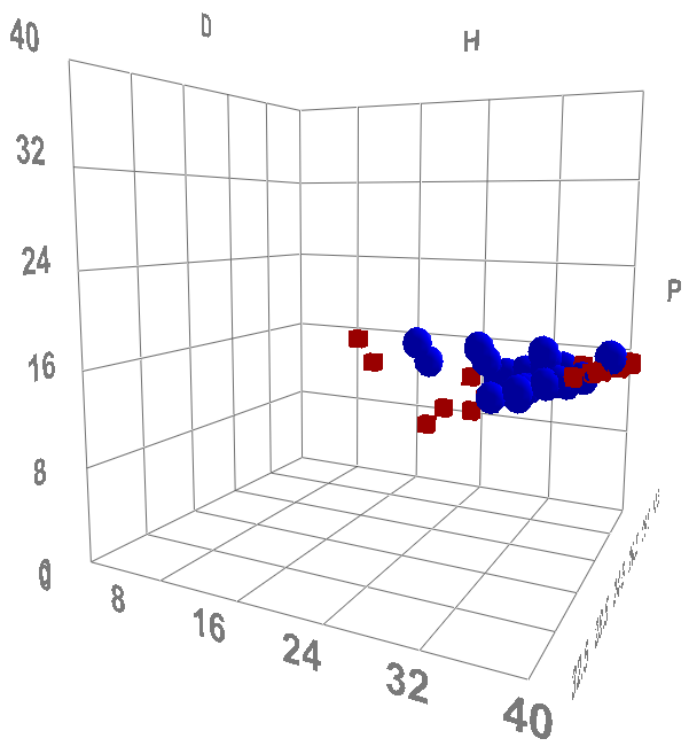

Fig. 2 Solubility data from Fan et $a l^{52}$ for a two-component LMWG, represented in Hansen space. The gelated liquids ( $G$ ) are represented by blue points; both good solvents (S) and non-solvents (I) are represented

by red points. The plot is generated with the HSPiP software. ${ }^{59}$

\section{The traps of the Teas plot representation}

The full HSP approach with three parameters is thus quite successful but unfortunately requires the use of a software that allows to generate $3 \mathrm{D}$ plots. In order to alleviate this graphical representation drawback, several authors proposed to use a $2 \mathrm{D}$ representation called Teas plot. ${ }^{43,47,49,53}$ The idea is to normalize the HSPs to be able to plot them in a triangular 2D representation with coordinates:

$$
\begin{aligned}
f_{d} & =\frac{\delta_{d}}{\delta_{d}+\delta_{p}+\delta_{h}} \\
f_{p} & =\frac{\delta_{p}}{\delta_{d}+\delta_{p}+\delta_{h}} \\
f_{h} & =\frac{\delta_{h}}{\delta_{d}+\delta_{p}+\delta_{h}}
\end{aligned}
$$
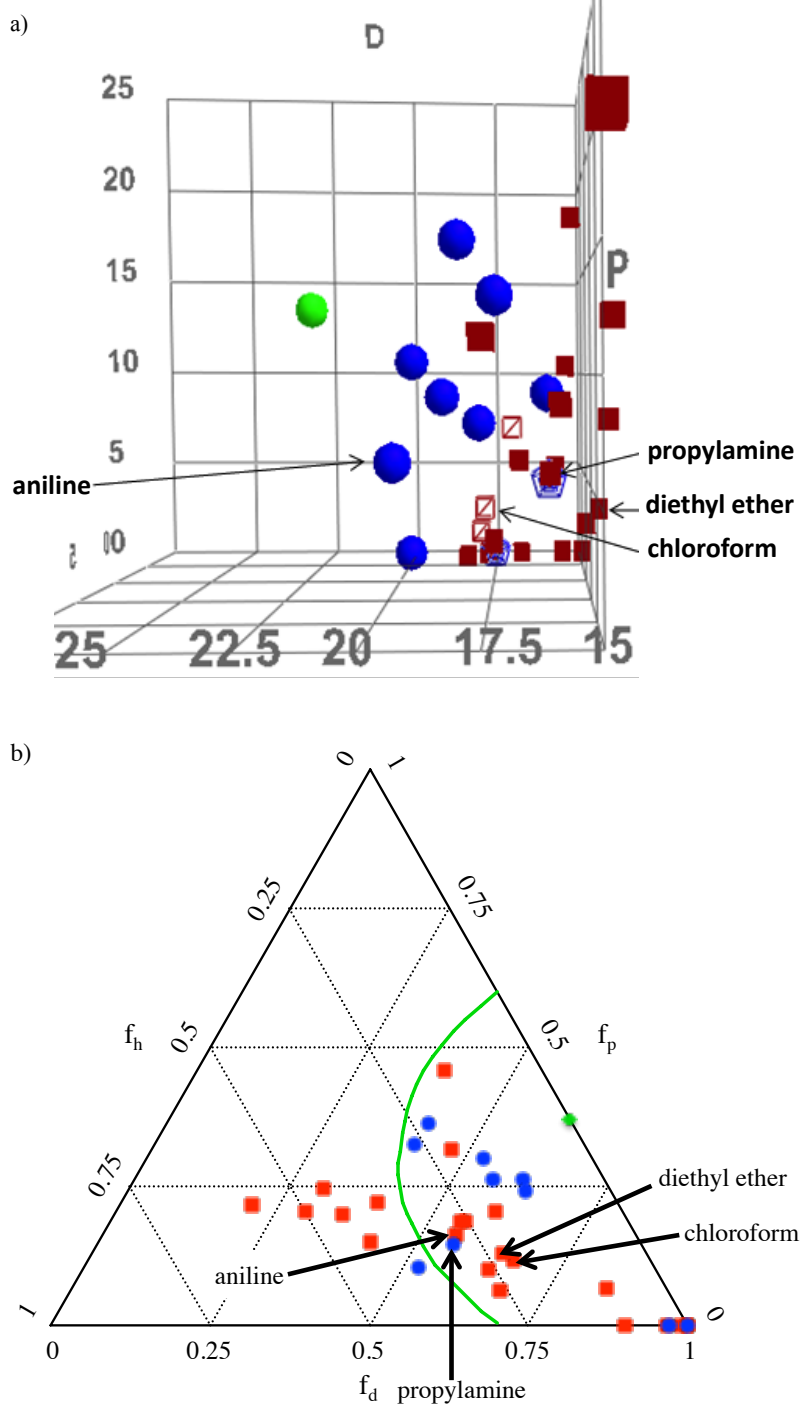

Fig. 3 Solubility data from Shinkai et al. ${ }^{68}$ for cholesterol-based LMWG 2Me, represented in Hansen space (a) and in a Teas plot (b). The gelated liquids $(G)$ are represented by blue points; both good solvents $(S)$ and non-solvents (I) are represented by red points. The centre of the gelation sphere and the projection of the sphere on the Teas plot are in green.

While this approach appears to be successful in cases when a limited number of data points are available and while it is undeniably simple to manipulate, one has to realize that the Teas plot formula has no theoretical justification and that the representation can be misleading. Indeed, two points that are close to each other in the 3D Hansen space representation are also close to each other in the Teas plot representation, but the reverse is not true. For instance, diethyl ether $\left(\delta_{d}^{S}=14.5, \delta_{p}^{s}=2.9, \delta_{h}^{S}=\right.$ $\left.4.6 \mathrm{MPa}^{1 / 2}\right)$ and chloroform $\left(\delta_{d}^{S}=17.8, \delta_{p}^{s}=3.1, \delta_{h}^{S}=5.7 \mathrm{MPa}^{1 / 2}\right)$ are far apart in the $3 \mathrm{D}$ plot, which reflects their well known solubility differences, but they are nearly at the same location in the Teas plot (Fig. 3). Consequently, it is not surprizing that in some cases the solubility data correlation visible in a 3D representation is blurred in a Teas plot (Fig. 3). This example clearly contradicts the claim that the gelation can be predicted based on Teas plot representation of HSPs. ${ }^{47}$ 
The gelation sphere and the solubility sphere do not necessarily have the same centre

Organogel formation requires a suitably balanced solubility, because the gelator should be soluble at high temperature and should assemble without precipitating at room temperature. Therefore it is reasonable to expect that the gelation domain is situated close to the solubility domain in Hansen space. Several authors went a step further and assumed that the gelation domain and the solubility domain have the same centre. ${ }^{45,46,49}$ This leads to a core-shell graphical representation with two concentric spheres, where the solubility domain is in the core and the gelation domain is in the shell. Although this particular repartition of the solubility and gelation data might be observed in some cases, the data presented up to now does not unambiguously prove it because of the scarcity of data points (see Figs. S4 and S5). Moreover, most of the examples described in reference 42 can clearly not be modelled by two concentric spheres, as shown in a particular example in Fig. 4. Therefore this model cannot be generally valid.

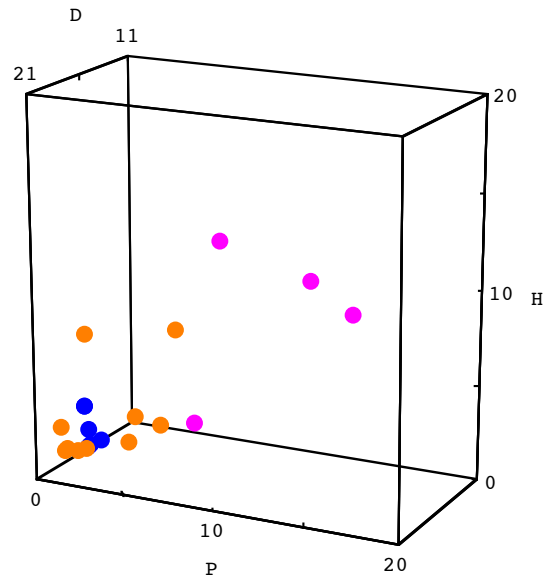

Fig. 4 Solubility data from Dastidar et al. ${ }^{69}$ for cinnamate-based LMWG 3BrCIN, represented in Hansen space. Blue: gel; magenta: soluble; orange: insoluble.

The centre of the gelation sphere cannot be estimated from group contribution

Several approaches have been developed to calculate the HSP of compounds by a group contribution method. ${ }^{70,71}$ These approaches are very useful when the HSPs cannot be measured experimentally. Therefore, it is tempting to calculate the HSPs for a gelator from its chemical structure by a group contribution method. ${ }^{43,48,49,54}$ However, one should realize that the value that is obtained may be a good approximation for the centre of the solubility sphere, but has no reason to be related to the centre of the gelation sphere, unless both domains are concentric, which remains to be proved (see above). For example, Fig. 5 shows in Hansen space the gelation data of reference 43 together with the point calculated for the gelator (12-hydroxystearic acid) by a group contribution method. ${ }^{43}$ This point is clearly not situated within the gelation domain. Therefore, the absence of correlation (that was noted by the authors) between gelation and the distance to the gelator is not surprizing. Another example, provided in Fig. S6, shows that the point obtained by group contribution is situated in the solubility domain, and not in the gelation domain.
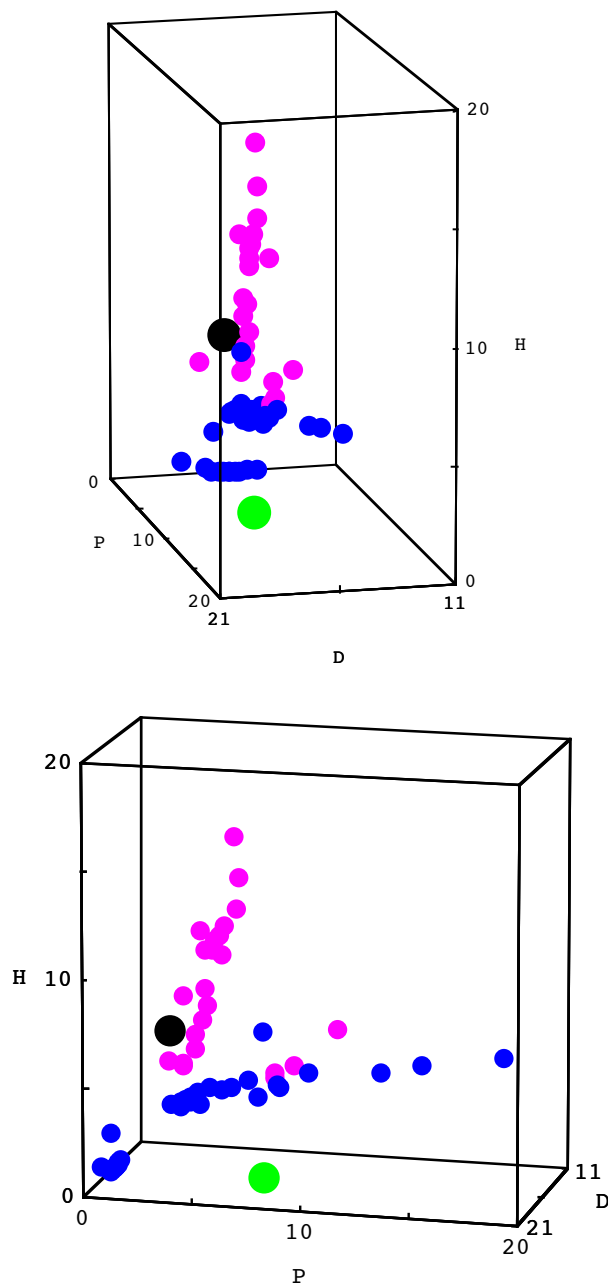

Fig. 5 Solubility data from Rogers et $a .^{43}$ for 12-hydroxystearic acid LMWG, represented in Hansen space. Blue: gel; magenta: soluble. The black point represents the coordinates calculated by Rogers et al. with a group contribution method for the gelator (12-hydroxystearic acid: $\delta_{d}=$ $\left.17.59, \delta_{p}=2.86, \delta_{h}=6.77 \mathrm{MPa}^{1 / 2}\right)$. The green point is the centre of the gelation sphere determined by the present method $\left(\delta_{d}=16.3, \delta_{p}=7.3\right.$,

$$
\left.\delta_{h}=0.1 \mathrm{MPa}^{1 / 2}, R=7.5 \mathrm{MPa}^{1 / 2}\right) \text {. }
$$

\section{The importance of kinetics}

In fact, one should be aware of an important difference when applying the HSP approach (i) to describe the solubility of polymers or (ii) to rationalize the gel formation of LMWGs. Indeed, the (polymer) solubility is an equilibrium property, whereas the gel formation is a kinetically controlled process. ${ }^{54}$ For instance, the viscosity of the liquid has been suggested to influence the stability of gels because it affects the diffusion rate of the gelator molecules in the liquid. ${ }^{47}$ Moreover, organogels are known to be metastable objects that may evolve toward a more stable precipitate or crystal characterized by a reduced interfacial area between the LMWG and the liquid. Such kinetic effects are definitely not taken into account in the HSP theory and may be responsible for some discrepancies between experiment and the HSP rationalization. Of course in order to minimize such effects, it is of utmost importance to use consistent preparation conditions within each study (i.e. the same concentration and cooling rate). 
The next step: rationalization of the gel stability (CGC and $\left.\mathbf{T}_{\mathrm{gel}}\right)$

The present HSP approach is quite successful in predicting if a given LMWG should form a gel in a given liquid. It would be highly interesting to be able to extend this yes/no information into a more quantitative prediction of the gel stability. Although no universal criteria is available yet, some interesting trends have been reported between the gel stability and HSPs. Within homologous series of liquids, the gelation temperature $\left(T_{\text {gel }}\right)$ below which the gel is stable or the critical gelator concentration (CGC) above which the gel is stable have been correlated to HSPs. ${ }^{36,43,45,56,72}$ It remains to be seen if this approach can be extended in order to be able to estimate the $\mathrm{T}_{\text {gel }}$ or the CGC without prior data on closely related liquids.

\section{HSP in practice}

\section{The acquisition of the solubility data}

Obviously, the robustness of the predictions that can be made based on this HSP approach heavily rests on the comprehensiveness of the solubility data available to determine the gelation sphere. Therefore, the choice of the test liquids is crucial. Ideally a high density of points in the Hansen space is desired, and this is especially true in the initially unknown regions where the behaviour switches from "gel" to "no gel". In order to acquire a comprehensive solubility data set at a reasonable experimental cost, we suggest a two-step procedure. In the first step, about 20 liquids of known HSPs are selected so that they are homogeneously scattered in Hansen space. Table S3 provides such a list of liquids with HSPs in the following range $\left(14.7<\delta_{d}^{s}<20,0<\delta_{p}^{s}<18,0<\delta_{h}^{s}<42.3 \mathrm{MPa}^{1 / 2}\right)$. Then gel formation is tested in these liquids. A priori any concentration of the gelator and any gel formation procedure can be selected, with the obvious caveat that the predictions based on these tests will only be relevant to the experimental conditions selected. Fig. 6a shows a typical data set obtained for a member of a well-known family of hydroxystearic amide based LMWG (C12). ${ }^{73}$ As expected, the gel forming liquids are grouped in a particular region of the Hansen space (low $\delta_{d}^{s}, \delta_{p}^{s}$ and $\delta_{h}^{S}$ ), but because of the relatively large distance between the experimental points, the determination of a gelation sphere (see below) cannot be precise. However, based on this preliminary data set it is now possible to select a second list of liquids focusing in the region in direct contact with the initial group of gel forming liquids. For this second step, it is possible to choose either new liquids or mixtures of the former liquids. To illustrate this, we have selected from the initial gelation data 5 gel forming liquids and 6 non-gel forming liquids and mixed them in various proportions to generate 44 new test liquids, the HSPs of which were calculated as the volume average of the pure liquids (Table S4). Fig. 6b shows the extended gel formation data obtained after the second step. We now have a very precise picture of the gelation domain.
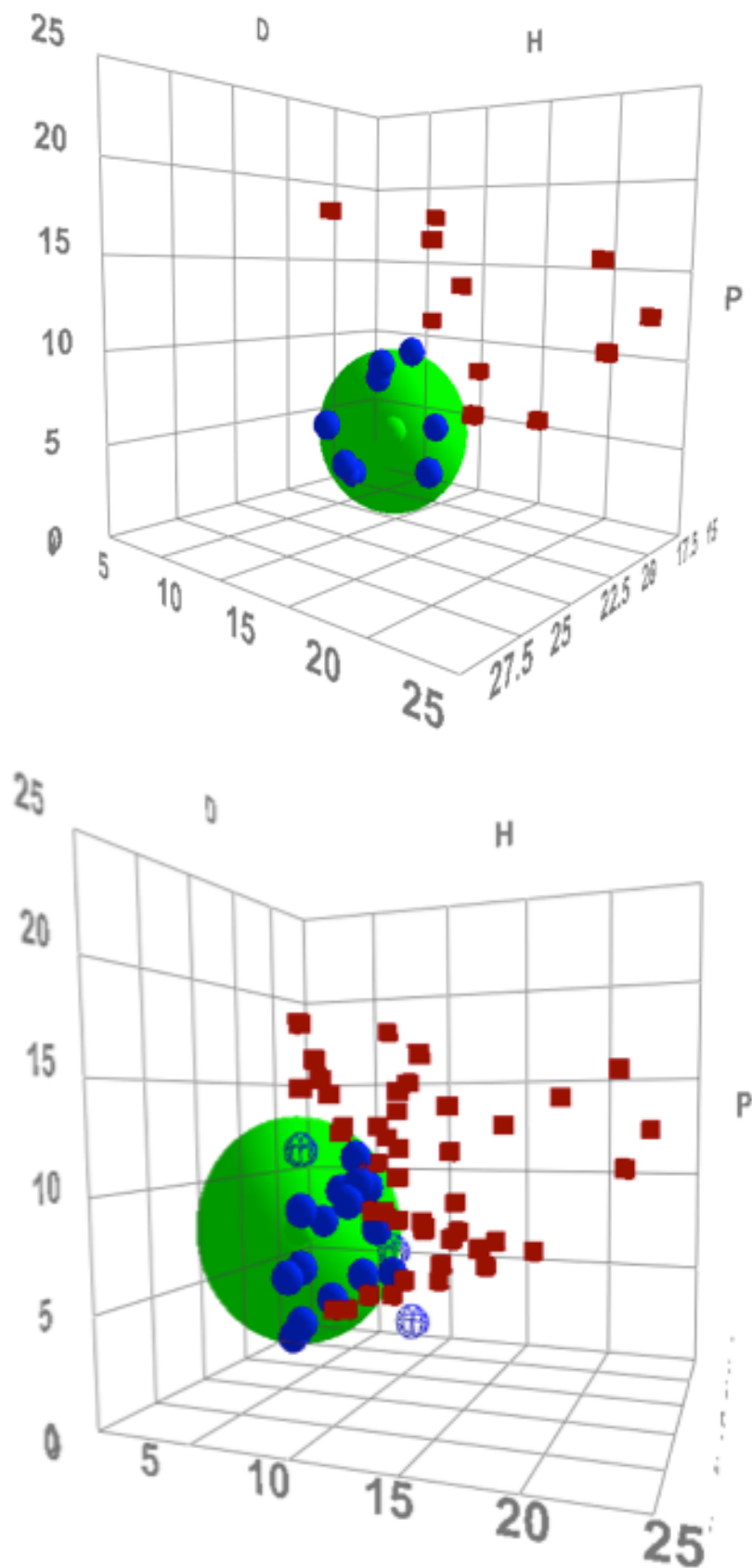

Fig. 6 Solubility data for hydroxystearic amide based LMWG C12, represented in Hansen space. The solubility was tested in the first step in 21 liquids (a) and in the second step in 44 additional liquid mixtures (b).

The gelated liquids ( $\mathrm{G}$ ) are represented by blue points; both good solvents (S) and non-solvents (I) are represented by red points. The gelation sphere is green. The plot is generated with the HSPiP software. ${ }^{59}$

\section{The determination of the gelation sphere}

The objective is to find the centre and the radius of a sphere, so that as many $\mathrm{G}$ liquids as possible lie inside the sphere, but as many $\mathrm{S}$ and I liquids as possible lie outside. This can be done straightforwardly with any basic spreadsheet software as exemplified in the Microsoft Excel spreadsheet provided in ESI. First, a table is created containing the HSPs of the test liquids and the results of the gelation test in the form of a column with values of 1 or 0 depending on whether a gel is formed or not. Then 
arbitrary values for the gelation sphere centre and radius are chosen and the distance between this centre and each test liquid is calculated. A mathematical criterion has to be applied to these distances to quantify in what measure the guessed centre and radius are suitable and to allow their optimization. Several such criteria can be used, but we found the procedure proposed by Gharagheizi et $a .^{74}$ to be particularly simple and effective, and we implemented it in the Microsoft Excel spreadsheet provided in ESI. The optimization of the gelation sphere can then be done manually or more conveniently with a minimization routine (the Solver function in the case of Microsoft Excel spreadsheet). This step is technically very simple but requires some critical evaluation, as is the case for any numerical minimization. In particular, the procedure should be repeated several times with distinct initial guesses to check the robustness of the final result. For instance, if the procedure is applied several times to the limited data of Fig. 6a, one realizes that several gelation spheres are possible and therefore that the uncertainty is high. In contrast, the same procedure applied to the extended data of Fig. 6b, reproducibly yields the same gelation sphere $\left(\delta_{d}=15.9, \delta_{p}=6.2\right.$, $\left.\delta_{h}=0.3 \mathrm{MPa}^{1 / 2}, R=6.8 \mathrm{MPa}^{1 / 2}\right)$. Finally, a visualization software is needed to plot the HSPs of the test liquids and the gelation sphere in a $3 \mathrm{D}$ plot. $^{75}$

Alternatively, one can use a specialized software dedicated to this task (HSPiP). ${ }^{59}$ This software contains a comprehensive list of HSPs for the test liquids and allows to perform both the numerical determination of the gelation sphere and its $3 \mathrm{D}$ visualization.

\section{Conclusion}

Based on solubility tests of a LMWG in a set of liquids, it is possible to define one (or more) gelation spheres. If the HSPs of an untested liquid (or of an untested mixture of liquids) fall in the gelation sphere, then this liquid or mixture of liquids is likely to be gelled by the LMWG. Of course, the reliability of the prediction will critically depend on the quality of the solubility data set, that can be significantly improved by a two-step procedure. This straightforward method should become a useful data mining tool, allowing to considerably reduce the number of trials usually involved during the identification of a suitable gelator for a particular application. Although the use of a Teas plot representation or of only one or two HSPs out of the three has been proposed to simplify the analysis, we stress that significant information is lost in the process. Moreover, the calculation of the gelator HSPs by a group contribution method cannot yield the centre of the gelation sphere.

\section{Acknowledgments}

Prof. Steven Abbott is gratefully acknowledged for sharing his insight and providing us with the HSPiP software. Financial support from Total company is also acknowledged.

\section{Notes and references}

${ }^{a}$ Sorbonne Université, UPMC Univ Paris 06, UMR 8232, IPCM, Chimie des Polymères, F-75005 Paris, France.
${ }^{b}$ CNRS, UMR 8232, IPCM, Chimie des Polymères, F-75005 Paris, France

$\dagger$ Electronic Supplementary Information (ESI) available: Additional solubility data; excel file for the determination of the gelation sphere. See DOI: $10.1039 / \mathrm{b} 000000 \mathrm{x}$

1. Molecular Gels: Materials with Self-Assembled Fibrillar Networks, ed. P. Terech and R. G. Weiss, Springer, Dordrecht, 2006.

2. M. George and R. G. Weiss, Acc. Chem. Res., 2006, 39, 489.

3. M. Lescanne, P. Grondin, A. d'Aléo, F. Fages, J.L. Pozzo, O. Mondain Monval, P. Reinheimer and A. Colin, Langmuir, 2004, 20, 3032.

4. P. Mukhopadhyay, N. Fujita, A. Takada, T. Kishida, M. Shirakawa, and S. Shinkai, Angew. Chem. Int. Ed., 2010, 49, 6338.

5. J. Brinksma, B. L. Feringa, R. M. Kellogg, R. Vreeker and J. van Esch, Langmuir, 2000, 16, 9249.

6. G. Ducouret, C. Chassenieux, S. Martins, F. Lequeux and L. Bouteiller, J. Colloid Interface Sci., 2007, 310, 624.

7. S. Tang, X. Y. Liu and C. S. Strom, Adv. Funct. Mater., 2009, 19, 2252.

8. A. R. Hirst, B. Escuder, J. F. Miravet and D. K. Smith, Angew. Chem. Int. Ed., 2008, 47, 8002.

9. A. Dawn, T. Shiraki, S. Haraguchi, S.-I. T., and S. Shinkai, Chem. Asian J., 2011, 6, 266.

10. E. Sabadini, K. R. Francisco and L. Bouteiller, Langmuir, 2010, 26, 1482.

11. S. Matsumoto, S. Yamaguchi, S. Ueno, H. Komatsu, M. Ikeda, K. Ishizuka, Y. Iko, K. V. Tabata, H. Aoki, S. Ito, H. Noji and I. Hamachi, Chem. Eur. J., 2008, 14, 3977.

12. S. I. Stupp, Nano Lett., 2010, 10, 4783.

13. P. Cintas and G. Cravotto, Chem. Soc. Rev., 2009, 38, 2684

14. H. Maeda, Chem. Eur. J., 2008, 14, 11274.

15. S.-I. Kawano, N. Fujita, and S. Shinkai, J. Am. Chem. Soc., 2004, 126, 8592.

16. J. J. D. de Jong, L. N. Lucas, R. M. Kellogg, J. H. van Esch and B. L. Feringa, Science, 2004, 304, 278.

17. S. Yagai, T. Nakajima, K. Kishikawa, S. Kohmoto, T. Karatsu and A. Kitamura, J. Am. Chem. Soc., 2005, 127, 11134.

18. P. Mukhopadhyay, Y. Iwashita, M. Shirakawa, S. Kawano, N. Fujita and S. Shinkai, Angew. Chem. Int. Ed., 2006, 45, 1592.

19. M.-O. M. Piepenbrock, G. O. Lloyd, N. Clarke, J. W. Steed, Chem. Rev., 2010, 110, 1960.

20. D. Bardelang, M. B. Zaman, I. L. Moudrakovski, S. Pawsey, J. C. Margeson, D. Wang, X. Wi, J. A. Ripmeester, C. I. Ratcliffe and K. Yu, Adv. Mater., 2008, 20, 4517

21. I. Yoshimura, Y. Miyahara, N. Kasagi, H. Yamane, A. Ojida, and I. Hamachi, J. Am. Chem. Soc., 2004, 126, 12204.

22. D. B. Amabilino and J. Puigmarti-Luis, Soft Matter, 2010, 6, 1605.

23. J. H. Jung, M. Parka and S. Shinkai, Chem. Soc. Rev., 2010, 39, 4286.

24. T. Kato, Y. Hirai, S. Nakaso and M. Moriyama, Chem. Soc. Rev., 2007, 36, 1857.

25. J.-H. Wan, L.-Y. Mao, Y.-B. Li, Z.-F. Li, H.-Y. Qiu, C. Wang and G.-Q. Lai, Soft Matter, 2010, 6, 3195.

26. S. Kawano, N. Fujita and S. Shinkai, Chem. Eur. J., 2005, 11, 4735.

27. S. J. George and A. Ajayaghosh, Chem. Eur. J., 2005, 11, 3217.

28. S. Yagai, S. Kubota, T. Iwashima, K. Kishikawa, T. Nakanishi, T. Karatsu and A. Kitamura, Chem. Eur. J., 2008, 14, 5246.

29. S. S. Babu, V. K. Praveen, and A. Ajayaghosh, Chem. Rev., dx.doi.org/10.1021/cr400195.

30. J. A. Foster and J. W. Steed, Angew. Chem. Int. Ed., 2010, 49, 6718.

31. M. Raynal, F. Portier, P. W. N. M. van Leeuwen and L. Bouteiller, J. Am. Chem. Soc., 2013, 135, 17687.

32. F. Hapiot, S. Menuel, and E. Monflier, ACS Catal., 2013, 3, 1006

33. B. Isare, L. Petit, E. Bugnet, R. Vincent, L. Lapalu, P. Sautet and L. Bouteiller, Langmuir, 2009, 25, 8400 .

34. A. Aggeli, M. Bell, N. Boden, J. N. Keen, P. F. Knowles, T. C. B. McLeish, M. Pitkeathly and S. E. Radford, Nature, 1997, 386, 259.

35. J. Makarevic, M. Jokic, B. Peric, V. Tomisic, B. Kojic-Prodic and M. Zinic, Chem. Eur. J., 2001, 7, 3328.

36. A. R. Hirst and D. K. Smith, Langmuir, 2004, 20, 10851. 
37. W. Frässdorf, M. Fahrländer, K. Fuchs and C. Friedrich, J. Rheol., 2003, 47, 1445 .

38. W. Edwards, C. A. Lagadec and D. K. Smith, Soft Matter, 2011, 7, 110.

39. C. Lagadec and D. K. Smith, Chem. Commun., 2011, 47, 340.

40. K. Hanabusa, M. Matsumoto, M. Kimura, A. Kakehi and H. Shirai, J. Colloid Interface Sci., 2000, 224, 231.

41. M. L. Muro-Small, J. Chen and A. J. McNeil, Langmuir, 2011, 27, 13248.

42. M. Raynal and L. Bouteiller, Chem. Commun., 2011, 47, 8271.

43. J. Gao, S. Wu and M. A. Rogers, J. Mater. Chem., 2012, 22, 12651.

44. V. C. Edelsztein, A. S. Mac Cormack, M. Ciarlantini and P. H. Di Chenna, Beilstein J. Org. Chem., 2013, 9, 1826.

45. N. Yan, Z. Xu, K. K. Diehn, S. R. Raghavan, Y. Fang and R. G. Weiss, Langmuir, 2013, 29, 793.

46. N. Yan, Z. Xu, K. K. Diehn, S. R. Raghavan, Y. Fang, and R. G. Weiss, J. Am. Chem. Soc., 2013, 135, 8989.

47. H. Xu, J. Song, T. Tian and R. Feng, Soft Matter, 2012, 8, 3478.

48. K. Fan, L. Niu, J. Li, R. Feng, R. Qu, T. Liu and J. Song, Soft Matter, 2013, 9, 3057.

49. Y. Wu, S. Wu, G. Zou and Q. Zhang, Soft Matter, 2011, 7, 9177.

50. P. Curcio, F. Allix, G. Pickaert and B. Jamart-Grégoire, Chem. Eur. J., 2011, 17, 13603 .

51. C. Zhao, H. Wang, B. Bai, S. Qu, J. Song, X. Ran, Y. Zhang and M. Li, New J. Chem., 2013, 37, 1454.

52. L. Niu, J. Song, J. Li, N. Tao, M. Lu and K. Fan, Soft Matter, 2013, 9, 7780 .

53. F. Aparicio, F. Garcia and L. Sanchez, Chem. Eur. J., 2013, 19, 3239.

54. L. Feng and K. A. Cavicchi, Soft Matter, 2012, 8, 6483.

55. J. G. Hardy, A. R. Hirst and D. K. Smith, Soft Matter, 2012, 8, 3399.

56. S. Wu, J. Gao, T. J. Emge and M. A. Rogers, Soft Matter, 2013, 9, 5942.

57. C. M. Hansen, Hansen Solubility Parameters: A User's Handbook $2^{\text {nd }}$ Ed.; CRC Press LLC: Boca Raton, FL, 2007

58. C. M. Hansen, Progress Org. Coat., 2004, 51, 77.

59. S. J. Abbott, C. M. Hansen, H. Yamamoto, Hansen Solubility Parameters in Practice software, eBook, datasets, www.hansensolubility.com

60. J. H. van Esch and B. L. Feringa, Angew. Chem. Int. Ed., 2000, 39, 2263.

61. A. R. Hirst, I. A. Coates, T. R. Boucheteau, J. F. Miravet, B. Escuder, V. Castelletto, I. W. Hamley and D. K. Smith, J. Am. Chem. Soc., 2008, 130, 9113

62. J. W. Steed, Chem. Commun., 2011, 47, 1379.

63. J. H. van Esch, Langmuir, 2009, 25, 8392.

64. S. Wu, J. Gao, T. J. Emge and M. A. Rogers, Cryst. Growth Des., 2013, 13, 1360.

65. J. Gao, S. Wu, T. J. Emge and M. A. Rogers, CrystEngComm, 2013, 15, 4507

66. N. Yan, G. He, H. Zhang, L. Ding and Y. Fang, Langmuir, 2010, 26, 5909 .

67. carbon tetrachloride, 1-methylnaphthalene and p-xylene.

68. K. Murata, M. Aoki, T. Suzuki, T. Harada, H. Kawabata, T. Komori, F. Ohseto, K. Ueda and S. Shinkai, J. Am. Chem. Soc., 1994, 116, 6664

69. D. R. Trivedi, A. Ballabh, P. Dastidar and B. Ganguly, Chem. Eur. J., 2004, 10, 5311.

70. E. Stefanis, C.Panayiotou, Int. J. Thermophys., 2008, 29, 568.

71. J. Brandrup, E.H. Immergut, E.A. Grulke, Polymer Handbook, fourth ed., Wiley, New York, 1999.

72. W. Edwards and D. K. Smith, J. Am. Chem. Soc., 2013, 135, 5911

73. V. A. Mallia, M. George, D. L. Blair and R. G. Weiss, Langmuir, 2009, 25, 8615 .

74. F. Gharagheizi, J. Appl. Polym. Sci., 2007, 103, 31.

75. We have used Mathematica software. 